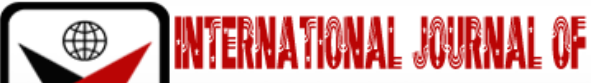

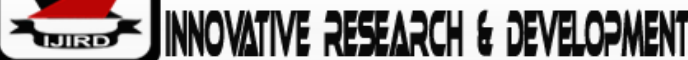

ISSN 2278-0211 (Online)

\section{Impacts of Social Support on Quality of Life of Cancer Patients in Kenya}

\author{
Mary Kung'u \\ Student, Department of Community Health and Reproductive Health Nursing, \\ Kenyatta University, Nairobi, Kenya \\ Lister Onsongo \\ Lecturer, Department of Community Health and Reproductive Health Nursing, \\ Kenyatta University, Nairobi, Kenya \\ James 0. Ogutu \\ Lecturer, Department of Pathology Department, School of Medicine, \\ Kenyatta University, Nairobi, Kenya
}

\begin{abstract}
:
Background: Cancer is the second leading cause of death worldwide after cardiovascular disease and accounts for 1 in 6 deaths. In Kenya, It accounts for 7\% of all death. One of the major concerns in determination of patients' quality of life is their social wellbeing. Cancer patients' response to diagnosis and treatment is dependent on both professional and social support they receive. Lack of social support has been linked with increase in depression, anxiety and lack of coping resulting to decreased emotional wellbeing as well as poor quality of life. Therefore, the aim of the study was to determine the impact of social support on quality of life of cancer patients in Kenya.

Methods: A descriptive cross-sectional research design was used for the study. Closed self-administered questionnaires were used for data collection which included the Quality of Life Patient/Cancer Survivor Version (QOL-CSV) questionnaire and the multidimensional Scale of Perceived Social Support questionnaire. Both were adopted and modified for the study. The study included 108 cancer patients selected through systematic random sampling technique.

Results: Majority of the cancer patients had good social support from family and significant others with most reporting lack of social support from friends. Bivariate analysis showed statistically significant relationship between quality of life with family social support, significant others social support, and financial support. Financial support, Family and significant others social support were identified to be predictors of quality of life.

Conclusions: Social support is an important element in determination of patients' quality of life. Health care workers, family and friends should not only focus on the diagnosis and treatment of the cancer but also should consider the social wellbeing of the patients. They play a major role in improving the patients' social wellbeing hence the overall quality of life.
\end{abstract}

Keywords: Cancer patients, social support, quality of life

\section{Introduction}

Cancer is the second leading cause of death worldwide after cardiovascular disease and accounts for 1 in 6 deaths (WHO, 2018). About 10 million people develop cancer each year in which, more than 6 million deaths are reported from the disease. According to GLOBOCAN, 2018, it was estimated that by 2020, the number of new cancer patients will have reached 15 million. By 2040 it is foreseen that the burden of cancer will be anticipated to surpass 27 million new cases each year. This prediction shows a 50\% increase from the approximated 18.1 million cancer cases in 2018. It is also seen that low-income countries contribute to a majority of the $50 \%$ increase in the cancer cases. In sub-Saharan Africa, the cancer incidence burden is over 85\% and the estimated cancer deaths are around 506,000 ((Bray et al., 2018)

In Kenya, cancer is the third leading cause of mortality after infectious and cardiovascular diseases and it is the second leading cause of mortality among non-communicable diseases (Bray et al., 2018).It accounts for 7\% of all death. In 2018, 47887 cancer cases were reported among who 32987 died from the disease (GLOBOCAN, 2018).This is despite the noted improvement in diagnosing and treatment of the disease (Batawi et al., 2019).

The world health organization defines QoL as a person's understanding of their place in life in relation to culture and value systems and this involves the person's goals, standards, expectations and concerns (Kessler et al., 2004). One of the major concerns in QoL is the individual social wellbeing. Social wellbeing of the cancer patients may include their social support, social networks as well as their social integration. Social supports related to the individual conduct to personal relationship. It refers to resources an individual perceive to be available in both formal and informal 
relationships. Social networks involves the structures of individual ties while social integration refers to the extent to which individuals participate in public and private social interactions(Gottlieb \& Bergen, 2010). The study focused on the perceived social support available to cancer patients and its relationship with quality of life.

Cancer patients' response to diagnosis and treatment is as also dependent on both professional and social support he or she receives. This aims to alleviate stress, anxiety and depression which results from the diagnosis and treatment of cancer. Patients who lack professional and social support have decrease level of social wellbeing resulting to poor quality of life (Adam \& Koranteng, 2020).

Social support includes support from family, friends and people of significance to the patients' life. Several studies report that patients with good social support have better coping mechanisms to cancer diagnosis and treatment. Study by Spatuzzi et al., (2016) on effects of perceived social support from family and significant others for women with breast cancer reported that social support improved the emotional wellbeing of the cancer patients by reducing the stress levels. According to McGuire, 2014study among cancer patients, social support not only reduced the stress levels but also resulted to improved knowledge of the cancer diagnosis as well as alleviated anxiety among the cancer patients. This as a result led to improved quality of life.

Lack of social support has been linked with increase in depression, anxiety and lack of coping resulting to decreased emotional wellbeing as well as poor quality of life (Penedo et al., 2012) . Several studies have identified several social support factors and their relationship with quality of life. There is little information in relation to social support and quality of life among cancer patients in Kenya. Therefore, the aim of the study was to determine availability of social support among cancer patients in Kenya.

\section{Material and Methods}

\subsection{Design and Data Collection Methods}

A descriptive cross-sectional research design was used for the study. Closed self-administered questionnaires were used for data collection which included the Quality of Life Patient/Cancer Survivor Version (QOL-CSV) questionnaire and the multidimensional Scale of Perceived Social Support questionnaire. Both were adopted and modified for the study. The study included 108 cancer patients

\subsection{Inclusion and Exclusion Criteria}

The inclusion included patients above 18 years and had a diagnosis of cancer by tissue histology or cytology, who gave informed written consent and were stable with ability to express themselves in both English and Kiswahili language. Patients with other conditions apart from the cancer diagnoses and those who declined consent were excluded from the study.

\subsection{Data Collection Methods}

The researcher identified participants eligible for the study, explained to them the aim of the study and those who provided informed consent were recruited .Questionnaire comprising of the Quality of Life Patient/Cancer Survivor Version (QOL-CSV) and multidimensional Scale of Perceived Social Support (MSPSS) section was included. QOL-CSV comprised of 41 items based on the likerts scale of 0-10.The MSPSS section comprised of 12 items with a likerts scale from strongly agree to strongly disagree.

\subsection{Data Analysis}

Data was analyzed using SPSS version 25.0 statistical tool. The sociodemographic characteristics and the patients' perceived social support level were analyzed using frequency, percentages and mean.Chi- square correlation was conducted to examine relationship between patients' perceived social support and quality of life

\subsection{Ethical Approval}

Ethical approval for the study was sought from Kenyatta University Ethical Review Committee (KUERC), National Commission for Science, Technology, and Innovation (NACOSTI) and the Kijabe Hospital ethical review team. Each respondent was given a written consent before introduction of the study and any personal concerns about the study by the subjects were addressed by the researcher.

\section{Results}

\subsection{Sociodemographic Characteristics and Patient Quality of Life}

The sample consisted of 108 cancer survivors with a mean age of 51years. Majority of the respondents were married $45.4 \%(n=49)$, female $52.8 \%$ with secondary level of education $38 \% .39 \%$ of the respondents were employed and earning a salary.Most with income had an income of about ksh.30000-ksh.60000 33(30.6\%), (Table 1).

The QOL-CSV questionnaire containing domains were used to assess the overall respondent's quality of life. The domain scores were scaled in a positive direction in which higher scores represented good quality of life and lower scores represented poor quality of life. The negative statements were reverse coded so as that the desired response for a respondent with a high quality of life was accorded a maximum score of 5 . The values of the four domains (physical domain, social relationships domain, psychological domain and environmental domain) were added. A score of above $45 \%$ 
represents a high quality of life while below 45\% represents a low quality of life. Majority of the respondents had good quality of life $58(46.3 \%)$ with $50(46.3 \%)$ having poor QoL(Table 1$)$.

\begin{tabular}{|c|c|c|}
\hline Variables & & $\mathbf{N}(\%)$ \\
\hline Gender & Male & $51(47.2)$ \\
\hline & Female & $57(52.8)$ \\
\hline Marital status & Single & $17(15.7)$ \\
\hline & Married & $49(45.4)$ \\
\hline & Separated & $11(11.2)$ \\
\hline & Widowed & $31(28.7)$ \\
\hline Education level & Non-basic & $17(15.7)$ \\
\hline & Primary & $18(16.7)$ \\
\hline & Secondary & $41(38.0)$ \\
\hline & College & $21(19.4)$ \\
\hline Employment status & University & $11(10.2)$ \\
\hline & Employed & $39(36.1)$ \\
\hline & Self-employed & $34(31.5)$ \\
\hline & Not working & $35(32.4)$ \\
\hline Income & No income & $35(32.4)$ \\
\hline & Below ksh.10,000 & $11(10.2)$ \\
\hline & ksh.10,001-30,000 & $33(30.6)$ \\
\hline & ksh.30,001-60,000 & $24(22.2)$ \\
\hline & ksh.60,001-100,000 & $5(4.6)$ \\
\hline & Good & $58(46.3)$ \\
\hline & Poor & $50(53.7)$ \\
\hline
\end{tabular}

Table 1: Sociodemographic Characteristics ( $N=108)$ Key: $N=$ Frequency, \%-Percentage

\subsection{Availability of Social Support for Cancer Patients}

Majority 53(40.5\%) of the respondents agreed that there were special people providing support to them and the special persons were a real source of comfort to them $61(46.6 \%)$.Most of the respondents strongly agree that family really tried to help 34(26\%) and was willing to help them in decision making 58(44.3\%).However majority strongly disagreed of having friends they could count on when things went wrong 72(55\%) (Table 2).Majority of the respondents were contented with information support on cancer diagnosis (47(43.5\%), information support on treatment options $66(33.3 \%)$ and also on follow up post treatment $40(37.0 \%)($ Table 3$)$.

\begin{tabular}{|c|c|c|c|c|c|}
\hline & $\begin{array}{c}\text { Strongly } \\
\text { agree } \\
\text { N (\%) }\end{array}$ & $\begin{array}{l}\text { Agree } \\
\text { N (\%) }\end{array}$ & $\begin{array}{l}\text { Neutral } \\
\text { N (\%) }\end{array}$ & $\begin{array}{l}\text { Disagree } \\
\mathrm{N}(\%)\end{array}$ & $\begin{array}{l}\text { Strongly } \\
\text { Disagree }\end{array}$ \\
\hline $\begin{array}{l}\text { 1.Thereisaspecialpersonwho } \\
\text { is aroundwhenIaminneed }\end{array}$ & $33(25.2)$ & $53(40.5)$ & $10(7.6)$ & $11(8.4)$ & $0(0.0)$ \\
\hline 2.My family really tries to help me. & $34(26)$ & $25(19.1)$ & $27(20.6)$ & $11(8.4)$ & $11(8.4)$ \\
\hline $\begin{array}{l}\text { 3.I haveaspecialpersonwhois } \\
\text { Arealsourceofcomforttome }\end{array}$ & $61(46.6)$ & $1((8.0)$ & $35(26.7)$ & $11(8.4)$ & $0(0.0)$ \\
\hline 4. Myfriendsreallytrytohelp me & $11(8.4)$ & $39(29.8)$ & $25(19.1)$ & $39(29.8)$ & $33(25.2)$ \\
\hline $\begin{array}{l}\text { 5.I can count on my friends when } \\
\text { things go wrong. }\end{array}$ & $11(8.4)$ & $1((8.0)$ & $0(0.0)$ & $24(18.3)$ & $72(55)$ \\
\hline $\begin{array}{l}\text { 6. I can talk about my problems with } \\
\text { my family }\end{array}$ & $0(0.0)$ & $70(53.4)$ & $11(8.4)$ & $0(0.0)$ & $27(20.6)$ \\
\hline $\begin{array}{l}\text { 7. There is a special person in my } \\
\text { Life who cares about my feelings. }\end{array}$ & $27(20.6)$ & $33(25.2)$ & $25(19.1)$ & $22(16.8)$ & $1(0.8)$ \\
\hline $\begin{array}{l}\text { 8. My family is willing to help me } \\
\text { make decisions }\end{array}$ & $58(44.3)$ & $1((8.0)$ & $22(16.8)$ & $3(2.8)$ & $24(18.3)$ \\
\hline
\end{tabular}

Table 2: Availability of Social Support for Cancer Patients ( $N=108)$

Key:N=Frequency, \%-Percentage 


\begin{tabular}{|c|c|c|}
\hline Variables & N (\%) & $46(42.6)$ \\
\hline Source Of Support & Health Care Workers & $54(50.0)$ \\
\hline & Family & $8(7.4)$ \\
\hline Information Support On Cancer Diagnosis & Friends & $47(43.5)$ \\
\hline & Very Well & $29(26.9)$ \\
\hline & Somewhat Well & $16(14.8)$ \\
\hline & Not So Well & $9(8.3)$ \\
\hline & Not At All Well & $8(7.4)$ \\
\hline Information Support Of Treatment & Extremely Well & $66(33.3)$ \\
\hline Options & Very Well & $15(13.9)$ \\
\hline & Somewhat Well & $13(12.0)$ \\
\hline & Not So Well & $11(10.2)$ \\
\hline & Not At All Well & $3(2.8)$ \\
\hline & Extremely Well & $40(37.0)$ \\
\hline Information Support Of Follow Up & Very Well & $48(44.4)$ \\
\hline & Somewhat Well & $18(17.1)$ \\
\hline & Not So Well & $2(1.9)$ \\
\hline & Not At All Well & $0(0.0)$ \\
\hline
\end{tabular}

Table 3: Availability of Support for Cancer Patients Key:N=Frequency, \%-Percentage

\subsection{Relationship between Perceived Social Support and Patients' Quality of Life}

Using Chi square test, the prevalence of having good quality of life is significantly $\left(X^{2}=14.102^{a}, p=0.029\right)$ higher among respondents who strongly agreed to have support from their significant/special persons compared to those who strongly disagreed with having the support. The proportion of those having good quality of life was significantly $\left(\mathrm{X}^{2}\right.$ $=16.546^{\mathrm{a}}, \mathrm{p}=0.011$ ) higher among individuals who strongly agreed to have received enough support from the family compared to those who did not receive enough support. Statistically significant relationship was identified between quality of life and patients financial support where patients with financial support had better quality of life than those who lacked financial support $\left(\mathrm{X}^{2}=13.557^{\mathrm{a}}, \mathrm{p}=0.001\right)$. There was no statically significant relationship between quality of life of the respondents and the support they got from friends $(\mathrm{p}=0.063)$.This is as shown on table 4 .

\begin{tabular}{|c|c|c|c|c|c|c|}
\hline \multirow[b]{2}{*}{$\begin{array}{l}\text { I have support from significant/special } \\
\text { persons }\end{array}$} & \multicolumn{6}{|c|}{ QUALITY OF LIFE } \\
\hline & Good & Poor & Total & Chi Square & Df & P value \\
\hline Strongly agree & 14 & 19 & 33 & $14.102^{\mathrm{a}}$ & 6 & .029 \\
\hline Agree & 24 & 29 & 53 & & & \\
\hline Neutral & 4 & 6 & 10 & & & \\
\hline Disagree & 7 & 4 & 11 & & & \\
\hline Strongly disagree & 0 & 0 & 0 & & & \\
\hline \multicolumn{7}{|l|}{ I have enough support from family } \\
\hline Strongly agree & 30 & 28 & 58 & $16.546^{\mathrm{a}}$ & 6 & .011 \\
\hline Agree & 1 & 0 & 1 & & & \\
\hline Neutral & 8 & 14 & 22 & & & \\
\hline Disagree & 1 & 3 & 4 & & & \\
\hline Strongly disagree & 11 & 13 & 24 & & & \\
\hline \multicolumn{7}{|l|}{ I have enough support from friends } \\
\hline Strongly agree & 12 & 15 & 27 & $1.702^{\mathrm{a}}$ & 3 & .063 \\
\hline Agree & 0 & 1 & 1 & & & \\
\hline Neutral & 23 & 22 & 45 & & & \\
\hline Disagree & 2 & 6 & 8 & & & \\
\hline Strongly disagree & 14 & 13 & 27 & & & \\
\hline \multicolumn{7}{|l|}{ Income } \\
\hline Not working & 11 & 35 & 46 & $12.396^{\mathrm{a}}$ & 6 & 0.013 \\
\hline Below ksh.10,000 & 13 & 20 & 33 & & & \\
\hline ksh.10,001-30,000 & 15 & 9 & 24 & & & \\
\hline ksh.30,001-60,000 & 4 & 1 & 5 & & & \\
\hline \multicolumn{7}{|l|}{ Receiving financial support } \\
\hline Yes & 44 & 9 & 53 & $13.557^{a}$ & 6 & .001 \\
\hline No & 6 & 49 & 55 & & & \\
\hline
\end{tabular}

Table 4: Relationship between Social Support and Patients' Quality of Life

Key: Sig P <.05 While CI 95\% 


\subsection{Predictors of Overall Qol}

Using variables that were significantly correlated with QoL, stepwise regression predicting overall QoL was done. Table 5 show that of $50 \%$ of variance in the Qol can be accounted by three predictors collectively $(F(5,102)=12.41$, $P<.001)$. Looking at individual contribution of the predictors, the results show that Support from special persons $(\beta=.195$, $t=2.739, p=.007)$, support from family members $(\beta=.173, t=2.523, p=.013)$ and financial support $(\beta=.217, t=3.164, p=.002)$ positively predict QoL (table 4).

\begin{tabular}{|c|c|c|c|c|c|c|c|c|}
\hline Variables & B & $\boldsymbol{\beta}$ & Df1 & Df2 & Adj. R & t & p & F \\
\hline (Constant) & 37.26 & & 5 & 102 & .500 & 3.025 & .003 & 12.411 \\
\hline Support from special persons & 9.078 & .195 & & & & 2.739 & .007 & \\
\hline Financial support & 9.169 & .217 & & & & 3.164 & .002 & 9.169 \\
\hline Support from family members & 3.297 & .173 & & & & 2.523 & .013 & \\
\hline
\end{tabular}

Table 5: Predictors of Overall Qol

Key: Sig P<.05 While CI 95\%, CI: Confidence Interval, B: Beta Coefficient, T: T Value While B Coefficient Is Significant, Adj. R2: Adjusted Coefficient of Determination

\section{Discussion}

The study shows that majority of the patients had good quality of life as they had a score above $45 \%$. The study results were similar to Thompson et al., (2017) study but contrary to Toni et al., (2017) study where majority of the respondents had poor quality of life. This could be due to differences in the sociodemographic characteristics and the treatment options of the patients. Patients in an older age group with advanced stages of the disease may have poor quality of life scores compared to the young at initial stages of the disease (Suwankhong et al., 2013)

The results of the study showed the importance of social support for the cancer patients. Majority responded to have received good social support from family and significant others. The results were similar to those of a study by Nilsson et al. (2013) among breast cancer patients undergoing reconstruction after mastectomy where patients with good communication from the family members had better quality of life compared to individual with poor relation with their family members. The results were contrary to a study by Penedo et al., (2012) on perceived social support as predictor to disease specific QoL where patients who received less informational support during follow up post treatment had poor quality of life. This may be due to disruption of continuity of care from health care personnel as most do not focus on follow up post treatment.

The results of the study showed that majority of the respondents had good information support from the health care workers in relation to the diagnosis, treatment options and follow up. The results were similar to those of a study on availability of social support on breast cancer patients where most stated to have received adequate information on medication and self-care from their health care providers (Adam \& Koranteng, 2020).The study also shows that most of the information support came from the health care providers while emotional support was obtained from family and significant others. The results were similar to those of Ishtiaq et al., (2019) and Adam et al., (2020) studies where emotional and tangible support of the patients was from the family members.

Majority of the respondents also stated to have less social support from friends. The results are similar to Penedo et al., (2012) study on perceived social support. The results may have been attributed by social avoidance practiced by cancer patients due to the diagnosis. Cancer patients feel a change in appearance hence keep off from their friends. Social avoidance results to decrease in the social wellbeing hence reduction in the overall quality of life.

The study demonstrated a statistical significant relationship between Qol and social support from family, significant other and financial support. Individuals who agreed to have strong social support from significant others had better QoL Compared to those who lacked good support from their partners. These results were similar to those of a study by Nilsson et al. (2013) among breast cancer patients undergoing mastectomy where patients with good support had better outcomes of mastectomy and reconstructive surgery as well as improved QoL compared to those who lacked good relation with their families.

Patients with high income had better Qol compared to those who were not working. Also individuals with financial support had better quality of life compared to those who lacked financial support. The results were similar to those of Adam \& Koranteng ,.).2020) qualitative study where majority who reported to have received financial support in paying medication and other important things had better QoL

The study finding shows that overall Qol was predicted by three variables including; family social support, significant others social support and financial support provided to the patients. The study was contrary to Penedo et al., (2012),Levine et al.,(2017), and Boatemaa et al.,(2020) studies. According to Penedo et al., (2012) study, healthcare workers behaviors and patients body image were the predictors of QoL. According to Levine et al.,(2017),factors predicting patients QoL included self-rated health and age. Positive social interactions was the overall predictor of QoL according to a study by Boatemaa et al.,(2020).The difference on the predictors of QoL may be due to the different variables included in the different studies.

The study shows the importance of social support to cancer patients from diagnosis, treatment and during follow up. The results also suggest the importance of maintaining perceived social support even after treatment completion and this play an important part in improving their quality of life. Availability of various forms of social support from health care workers, families, spouses and friend are important in yielding better impacts of the quality of life of the cancer patients. The study was limited to various forms of social support available to the cancer patients' hence further studies 
may be carried out on other supports such as spiritual support and the impacts of social support to the patients' quality of life.

\section{Funding}

The research did not receive any specific grant from funding agencies in the public, commercial, or not-for-profit sectors.

\section{References}

i. $\quad$ Bray, F., Ferlay, J., Soerjomataram, I., Siegel, R. L., Torre, L. A., \&Jemal, A. (2018). Global cancer statistics 2018 : Globocan estimates of incidence and mortality worldwide for 36 cancers in 185 countries. CA: A Cancer Journal for Clinicians, 68(6), 394-424. doi:10.3322/caac.21492

ii. Boatemaa Benson, R., Cobbold, B., OpokuBoamah, E., Akuoko, C. P., \&Boateng, D. (2020). Challenges, Coping Strategies, and Social Support among Breast Cancer Patients in Ghana. Advances in Public Health, 2020, 1-11. https://doi.org/10.1155/2020/4817932

iii. Gottlieb, B. H. (n.d.). Social support interventions. Encyclopedia of Human Relationships. doi:10.4135/9781412958479.n517

iv. Ishtiaq, M. (2019). Book review Creswell, J. W. (2014). Research design: Qualitative, quantitative and mixed methods approaches (4th ed.). Thousand Oaks, CA: Sage. English Language Teaching, 12(5), 40. doi:10.5539/elt.v12n5p40

v. Kim, J., JeongYeob Han, Shaw, B., McTavish, F., \& Gustafson, D. (2010). The roles of social support and coping strategies in predicting breast cancer patients' emotional well-being. Journal of Health Psychology, 15(4), 543552. doi:10.1177/1359105309355338

vi. Levine, E. G., Yoo, G. J., \& Aviv, C. (2017). Predictors of Quality of Life among Ethnically Diverse Breast Cancer Survivors. Applied Research in Quality of Life, 12(1), 1-16. https://doi.org/10.1007/s11482-016-9447-x

vii. McGuire S. World cancer report 2014. Geneva, Switzerland: World Health Organization, international agency for research on cancer, WHO Press, 2015.

viii. Nilsson, M. I., Petersson, L., Wennman-Larsen, A., Olsson, M., Vaez, M., \& Alexanderson, K. (2013). Adjustment and social support at work early after breast cancer surgery and its associations with sickness absence. PsychoOncology, 22(12), 2755-2762. doi:10.1002/pon.3341

ix. Penedo, F. J., Traeger, L., Benedict, C., Thomas, G., Dahn, J. R., Krause, M. H., \& Goodwin, W. J. (2012). Perceived social support as a predictor of disease-specific quality of life in head-and-Neck cancer patients. The Journal of Supportive Oncology, 10(3), 119-123. doi:10.1016/j.suponc.2011.09.002

x. Spatuzzi, R., Vespa, A., Lorenzi, P., Miccinesi, G., Ricciuti, M., Cifarelli, W., ...Aieta, M. (2016). Evaluation of social support, quality of life, and body image in women with breast cancer. Breast Care, 11(1), 28-32. doi:10.1159/000443493

xi. Suwankhong, D., \&Liamputtong, P. (2015). Social support and women living with breast cancer in the south of Thailand. Journal of Nursing Scholarship, 48(1), 39-47. doi:10.1111/jnu.12179

xii. WHO. Country cancer profiles. 2018, Accessed from https://www.who.int/cancer/country-profiles/gha_ en.pdf?ua=1

xiii. Thompson, T., Pérez, M., Kreuter, M., Margenthaler, J., Colditz, G., \&Jeffe, D. B. (2017). Perceived social support in African American breast cancer patients: Predictors and effects. Social Science \& Medicine, 192, $134-142$. doi:10.1016/j.socscimed.2017.09.035

xiv. Toni C., A., \& Jasmine A., M. (2017). Social relations and social support. Later-Life Social Support and Service Provision in Diverse and Vulnerable Populations, 8-26. doi:10.4324/9781315222950-2 